\title{
Educação a Distância, Ensino a Distância ou Ensino Não Presencial: do que se trata e como inovar no acesso ao conhecimento na era digital?
}

Gean Flávio de Araújo Lima;

Ricardo Triska

resumo:

O presente artigo é resultado de discussão sobre o tema Educação a Distância e Inovação na Gestão, ao longo de 3 anos anteriores a pandemia do Covid-19. A finalidade deste artigo é de promover o diálogo sobre os termos educação, ensino, distância física, presença virtual para identificar uma nomenclatura mais adequada as atividades de ensino remoto e discutir como inovar na modalidade. Ao longo da concepção desta pesquisa surgiu o distanciamento social, e as atividades remotas têm se tornado constante nos diversos canais que tratam sobre educação tornando o assunto ensino e educação mediado por plataformas digitais em voga. O levantamento bibliográfico serviu para orientar a construção do discurso. Como resultado foi percebeu-se que o caminho da busca intensa pela educação de qualidade pode ser obtido através do processo de inovação na gestão e que os princípios fundamentais da EAD podem permitir cada vez mais uma busca pela democratização da educação de qualidade, mas que o termo Educação deve ser usado com cautela quando há distanciamento.

\section{palavras-chave:}

Educação a distância; Ensino a Distância; Inovação; Gestão; Gestão de Design 


\section{Introdução}

O crescente surgimento de cursos na modalidade Educação a Distância tem se apresentado em números significativos, de 2005 a 2015 cresceu $354 \%{ }^{1}$ e, atualmente, são muitas as instituições que acrescentaram no seu mix de serviços cursos de EAD e divulgam nos diversos meios de comunicação, principalmente nos digitais, a fim de despertar o interesse e a confiabilidade de uma parcela do seu público-alvo.

A possibilidade de aquisição de conhecimento sem a necessidade de estar fisicamente presente no ambiente acadêmico e, além disso, escolher o melhor horário para se dedicar aos estudos apresentam-se como soluções bastante atraentes para aqueles que se veem com tempo escasso para a capacitação. Mas o que realmente tem se tornado esta modalidade em que o contato presencial com alunos, professores e instituição é transformado em uma relação distante fisicamente, mas fortemente presente no aspecto das relações sociais no âmbito virtual? Será mesmo que é educação? Ou será que é ensino? A ausência física existe, ou é um mero detalhe?

"A paradoxal simultaneidade de presença e ausência ensejada pelas mídias digitais ressignifica o conceito de educação a distância, substituindo-o pelo termo educação online ou mesmo educação em ambientes virtuais de aprendizagem (AVAs). (FILATRO E CAIRO, 2016, p.89.)"

As autoras supracitadas tratam exatamente do questionamento sobre o que é essa forma nova de aprender e ensinar, em que se propõe educar alguém que está separado fisicamente de seu educador, da instituição de ensino, de seus colegas de classe. Mas não fica claro se esta atividade realmente personifica o ato de educar. Neste artigo propomos uma discussão sobre os questionamentos apresentados anteriormente e a partir disso despertar o diálogo a respeito dos rumos do ensino e aprendizagem com o advento do uso das tecnologias da informação e comunicação no processo de gerenciamento da educação juntamente com o aprimoramento das técnicas educacionais para esta modalidade.

\section{Ensino, Educação ou Aprendizado a distância?}

Há tempos que se discute sobre os termos Educação, Ensino e Aprendizagem, alguns autores apontam a questão como um dilema. Para uns o termo educação não está apropriado para a modalidade, mas sim o termo Ensino e um dos defensores desta tese é Jesus (2013, p.1), onde cita que,

Embora chamada de Educação à Distância, deveria em vez ser denominada como Ensino à Distância, pois, em termos de formação de condutas e de desenvolvimento da criticidade, a EAD permanece em débito com a educação. Valores e condutas são construídos, sobretudo, pela convivência, relações interpessoais e experiências individuais e coletivas. Na EAD, esse convívio é bastante limitado.

O autor considera essencial a convivência e relações interpessoais no processo de educação, mas nos apropriaremos dos conceitos de Ensino, Educação e Aprendizagem para entendermos as características distintas entre eles, para isso usaremos a pesquisa de Romanzin (2001) a seguir.

\footnotetext{
${ }^{1}$ o volume de alunos matriculados em graduações a distância no Brasil pulou de 1,1 milhão para 5 milhões (ABED, 2017)
} 
Quadro 1 - Definição de Ensino, Educação e Aprendizagem

\begin{tabular}{|c|c|c|}
\hline Termo & Definição Dicionário Aurélio Eletrônico & Definição dicionário Houaiss \\
\hline ENSINO & $\begin{array}{l}\text { Transmissão de conhecimentos, } \\
\text { informações ou esclarecimentos úteis } \\
\text { ou indispensáveis à educação (2) ou a } \\
\text { um fim determinado; instrução. Esforço } \\
\text { orientado para a formação ou a } \\
\text { modificação da conduta humana; } \\
\text { educação. Adestramento, treinamento. }\end{array}$ & $\begin{array}{l}\text { Ato, processo ou efeito de } \\
\text { ensinar; ensinamento, } \\
\text { ensinança 1. transferência de } \\
\text { conhecimento, de informação, } \\
\text { esp. de caráter geral, instrução. } \\
2 \text { o sistema (e os métodos) } \\
\text { adequado a essa transferência. } \\
3 \text { o exercício do professorado; } \\
\text { magistério. 4. transmissão de } \\
\text { princípios que regulam a } \\
\text { conduta humana e a vida em } \\
\text { sociedade; educação. } 4.1 \text { fino } \\
\text { trato; cortesia; civilidade; } 5 . \\
\text { experiência adquirida por } \\
\text { vivência; lição, ensinamento. } 6 . \\
\text { admoestação, ensinadela, } \\
\text { repreensão. 7.amestramento, } \\
\text { adestramento, treinamento. }\end{array}$ \\
\hline EDUCAÇÃO & $\begin{array}{l}\text { Ato ou efeito de educar(-se). Processo } \\
\text { de desenvolvimento da capacidade } \\
\text { física, intelectual e moral da criança e } \\
\text { do ser humano em geral, visando à sua } \\
\text { melhor integração individual e social. } \\
\text { Os conhecimentos ou as aptidões } \\
\text { resultantes de tal processo; preparo. } \\
\text { Aperfeiçoamento integral de todas as } \\
\text { faculdades humanas. Conhecimento e } \\
\text { prática dos usos de sociedade; } \\
\text { civilidade, delicadeza, polidez, cortesia. } \\
\text { Arte de ensinar e adestrar animais; } \\
\text { adestramento. Arte de cultivar as } \\
\text { plantas e de as fazer reproduzir nas } \\
\text { melhores condições possíveis para se } \\
\text { auferirem bons resultados. }\end{array}$ & $\begin{array}{l}\text { 1. Ato ou processo de educar(- } \\
\text { se) } 1.1 \text { qualquer estágio desse } \\
\text { processo. 2. aplicação de } \\
\text { métodos próprios para } \\
\text { assegurar a formação e o } \\
\text { desenvolvimento físico, } \\
\text { intelectual e moral de um ser } \\
\text { humano; pedagogia, didática, } \\
\text { ensino. } 3 \text {. o conjunto desses } \\
\text { métodos; pedagogia, instrução, } \\
\text { ensino. } 4 \text {. desenvolvimento } \\
\text { metódico de uma faculdade, de } \\
\text { um sentido, de um órgão. } 5 \text {. } \\
\text { conhecimento e observação } \\
\text { dos costumes da vida social; } \\
\text { civilidade, delicadeza, polidez, } \\
\text { cortesia. } 6 \text {. adestramento de } \\
\text { animais. 7. aclimação de } \\
\text { plantas }\end{array}$ \\
\hline APRENDIZAGEM & $\begin{array}{l}\text { Ato ou efeito de aprender, } \\
\text { especialmente profissão manual ou } \\
\text { técnica. O exercício ou prática inicial da } \\
\text { matéria aprendida; experiência, } \\
\text { tirocínio. }\end{array}$ & $\begin{array}{l}\text { m.q. aprendizado: Ato, } \\
\text { processo ou efeito de aprender; } \\
\text { aprendizagem }\end{array}$ \\
\hline
\end{tabular}

Fonte: Adaptado do Dicionário Aurélio Eletrônico - século XXI - Versão $3.0(1999$, p.1) e do Dicionário Houaiss da Língua Portuguesa Versão 3.0 (2009) por Romanzin (2001)

Para Romanzin (2001), pela definição do dicionário o termo Ensino está mais ligado às atividades de instrução e treinamento. O termo Educação refere-se à prática, ao ato e ao processo e está, de certa maneira, vinculado à Arte. Aprendizagem refere-se mais ao ato ou ao efeito de aprender. De acordo com Consolo (2014), as definições do dicionário Houaiss, o termo Ensino está muito mais ligado à instrução, ao treinamento e à transmissão de informação, onde o foco se dá ao 
conteúdo (textos, vídeos, atividades com respostas automáticas), é um processo individualizado. Já Educação é um termo que se refere ao aperfeiçoamento, ao conhecimento e à prática, e ao contrário de Ensino o termo está ligado à interação entre pares, à construção do conhecimento em conjunto.

Sobre a Aprendizagem Demo (1998) cita que é a competência de reconstruir o saber acumulado de maneira permanente. Para Romanzin (2001), é, pois, aquisição de conhecimento ou habilidade e pode ser definida como um processo de integração e adaptação do ser ao ambiente em que vive, implicando, pois, mudanças de comportamento. É um processo que dura a vida inteira.

Demo (1998) enfatiza a inexistência de aprendizagem a distância afirmando que a distância se pode resolver muitas coisas que cercam a aprendizagem, como é o caso do acesso à informação, do estudo individual, da busca e coleta de dados, etc. Chaves (1999) também aponta para outra contradição para a expressão aprendizagem a distância: "A educação e a aprendizagem são processos que acontecem, de certo modo, dentro da pessoa - não há como possam ser realizados a distância".

A aprendizagem, para esses autores, é, então, o processo pelo qual o ser humano se prepara para fazer frente às novas situações. É o resultado de uma atividade do próprio homem, que desenvolve estratégias muito próprias para aprender. Ninguém aprende no lugar de outrem. Sob este ponto de vista, não há aprendizagem que não seja uma autoaprendizagem (ROMANZIN, 2001). O autor destaca que Ensino e Aprendizagem são os dois polos de um mesmo processo, entendido o ensino como a ação sistemática, ordenada e intencional de transmissão de conhecimentos e experiências, e a aprendizagem como o resultado dessa ação.

Tomando a expressão do dicionário Aurélio Eletrônico para Ensino, isto é: "Transmissão de conhecimentos, informações ou esclarecimentos úteis ou indispensáveis à educação ou a um fim determinado; instrução; esforço orientado para a formação ou a modificação da conduta humana...", pode-se afirmar que essa expressão está mais próxima de ser aceita, uma vez que ensinar é um processo externo, com a expressão "a distância". Desta forma, para Romanzin (2001), tem-se "Ensino a Distância" ou "Telensino" como a forma mais correta de expressão.

Chaves $(1999$, p.4) afirma que ensinar a distância é perfeitamente possível e completa,

hoje em dia, ocorre o tempo todo - como, por exemplo, quando se aprende através de um livro que foi escrito para ensinar alguma coisa, ou se assiste a um filme, programa de televisão, ou vídeo que foram feitos para ensinar alguma coisa, etc. A expressão "ensino a distância" faz perfeito sentido porque quem está ensinando - o "ensinante" está "espacialmente distante" (e também distante no tempo) de quem está aprendendo o "aprendente" (O termo "distância" foi originalmente cunhado para se referir ao espaço, mas pode igualmente ser bem aproveitado para se referir ao tempo).

Ensino é uma parte da educação, não é toda a educação. Educação é, essencialmente, o processo de desenvolvimento e formação da personalidade e tem por finalidade a formação do homem de caráter. A educação é um processo vital, para o qual concorrem forças naturais e espirituais, conjugadas pela ação consciente do educador e pela vontade livre do educando. Não pode, pois, ser confundida com o simples desenvolvimento ou crescimento dos seres vivos, nem com a mera adaptação do indivíduo ao meio. A educação é uma atividade criadora, que visa levar o ser humano a realizar as suas potencialidades físicas, intelectuais, morais e espirituais.

Em 20 de dezembro de 1996 é apresentado o Art. 80 no Título VIII, a Lei de Diretrizes e Bases da Educação Nacional n. 9.394 com relação à Educação a Distância. Nas Disposições Gerais que contém as determinações sobre a modalidade percebe-se inicialmente o uso do termo Ensino a Distância e em seguida nos incisos usa-se Educação a Distância, como se vê a seguir:

O Poder Público incentivará o desenvolvimento e a veiculação de programas de Ensino a Distância, em todos os níveis e modalidades de ensino, e de educação continuada.

$\S 1$ o A Educação a Distância, organizada com abertura e regime especiais, será oferecida por instituições especificamente credenciadas pela União.

$\S 20$ A União regulamentará os requisitos para a realização de exames e registro de diploma relativos a cursos de Educação a Distância. 
§ 3o As normas para produção, controle e avaliação de programas de Educação a Distância e a autorização para sua implementação, caberão aos respectivos sistemas de ensino, podendo haver cooperação e integração entre os diferentes sistemas.

§ 4o A Educação a Distância gozará de tratamento diferenciado, que incluirá: I - custos de transmissão reduzidos em canais comerciais de radiodifusão sonora e de sons e imagens;

II - concessão de canais com finalidades exclusivamente educativas; III - reserva de tempo mínimo, sem ônus para o Poder Público, pelos concessionários de canais comerciais.

Fica claro que o uso dos termos Ensino ou Educação para designar a modalidade ainda é uma dúvida até para o órgão normatizador. Romanzin (2001) afirma que a maioria dos autores provavelmente utiliza a expressão Educação a Distância evidenciando um processo externo ao indivíduo. Para Chaves (1999), como foi citado antes, que: “...são processos que acontecem, de certo modo, dentro da pessoa..." é um processo interno ao indivíduo. Chaves afirma ainda que

a expressão "teleducação" é, etimologicamente, sinônima de "educação a distância" e, portanto, padece dos mesmos vícios desta. Mas é uma expressão ainda mais inadequada do que "educação a distância", por sugerir aos desavisados que "teleducação" tem a ver com "educação pela televisão". Entretanto "teleducação" não representa educação por televisão, como o termo pode sugerir superficialmente. $\mathrm{O}$ inicial do termo vem do grego tele, ou seja, ao longe, ou, no caso da língua portuguesa, a distância. $\mathrm{O}$ mesmo sentido se pode adotar para a expressão teleaprendizagem.

Ao analisar os termos Ensino, Educação e Aprendizagem é possível entender o que sugere cada significado e, se consideramos a forma que o processo de educação se realiza, os autores citados concordam que a expressão mais correta deveria ser o Ensino a Distância.

\section{As tecnologias para EAD.}

A discussão abordada a partir deste ponto trata sobre a viabilidade técnica da modalidade EAD, pois durante todo o processo evolutivo da Educação a Distância o uso de recursos tecnológicos foram essenciais para o sucesso dos cursos nesta modalidade, mas nunca foi objeto de unanimidade (JESUS, 2013). O autor ainda cita que

Pelo correio, rádio ou TV, essa modalidade de ensino sempre foi limitada, pois, ainda que dialógico, raramente foi intersubjetivo como o ensino presencial. Com o advento do computador, mais especificamente do PC, smartphone e do tablet, especialmente com o desenvolvimento da INTERNET, o ensino à distância tornou-se um fato inevitável dentro do processo pedagógico. Embora não seja uma matriz de intersubjetividade, ele pode ser no mínimo dialógico e pode mesmo ensejar experiências de intersubjetividade. Além disso, o ensino à distância pode envolver melhor o aluno na aprendizagem.

Atualmente o processo de EAD tem sido auxiliado pelas Tecnologias de Informação e Comunicação, as TICs, que possibilitam a entrega do conteúdo ao aluno, o recebimento de atividades deste aluno e toda e qualquer interação entre aluno, instituição, professores e tutores. Sem as TICs a EAD não seria possível, mas além de prover o cidadão com as TICs, isto é, nesse caso, sobretudo, com o acesso à INTERNET, a sociedade precisaria preparar o cidadão para utilizá-la de maneira segura e crítica (JESUS, 2013). O autor completa que

Facilitar o acesso da maioria da população às TICs é um fato muito importante, porém insuficiente, pois, para que as mesmas exerçam seu papel de maneira adequada, é 
fundamental que os indivíduos sejam anteriormente preparados, para escolher as informações pertinentes nessa avalanche de fatos e notícias da atualidade.

Ao mesmo tempo que as TICs promovem o acesso ao universo educacional da EAD, o ambiente online pode ser hostil e com informações de diversas categorias, reais ou enganosas. $\mathrm{O}$ indivíduo tem que estar preparado para saber lidar com o que é útil e o que não é (BRASIL/INEP, 2011), fundada nas ideias alemãs de Bildung (formação) e Lehrung (instrução), as quais juntas comporiam o quadro da educação verdadeira. Isto é: Bildung + Lehrung = educação crítica (JESUS, 2013, p. 04). Estatisticamente há um aumento do acesso à educação online, mas se pode esquecer que as TICs, por si sós, não garantem a aquisição da competência crítica para escolher nessa cultura complexa (BRASIL/INEP, 2011).

As TICs devem ser encaradas com atitude crítica pois, ao considerarmos que o processo de aprendizagem por si só e exige um esforço do indivíduo para coletar informações novas e transformalas em conhecimento, a tecnologia que ajuda pode se transformar em um novo engodo para a sociedade dependente delas, pois elas não causam a aprendizagem. Isso seria retirar do cidadão aquilo a que tem direito: a informação completa (SLOTERDIJK, 2000).

$\mathrm{O}$ uso das novas tecnologias e da modalidade de EAD representa um grande avanço no ensino escolar, mas longe de ser um fim, são apenas importantes mediações no processo pedagógico. As questões da educação são mais complexas. As novas mediações e a nova modalidade de ensino devem ser vistas dentro de uma visão macrocurricular. Sobre este aspecto Jesus (2013) completa,

Seu uso permitiu à EAD conquistar enorme espaço na educação. Embora chamada de educação à distância, deveria em vez ser denominada como ensino à distância, pois, em termos de formação de condutas e de desenvolvimento da criticidade, a EAD permanece em débito com a educação. Valores e condutas são construídos, sobretudo, pela convivência, relações interpessoais e experiências individuais e coletivas. $\mathrm{Na}$ EAD, esse convívio é bastante limitado.

O que ficou claro aqui é que as novas tecnologias não transferem conhecimento para o aluno, pois o seu potencial está em motivar mais e facilitar a aprendizagem. Só o aluno pode aprender. E para o aluno da EAD existe chances de se desestimular com o curso, pois fatores como dificuldades acadêmicas do curso, domínio da tecnologia, conciliar estudo com emprego, questões financeiras e falta de acompanhamento devido podem transformar o processo de aprendizagem em fracasso.

\section{Ensino não Presencial, tendência para o ensino?}

A discussão anterior mostrou que, independentemente do termo usado (ensino ou educação) o aluno que optou pela modalidade EAD foi levado a esta escolha por motivos objetivos e claros: por não ter tempo de estar em sala de aula, pela facilidade de gerenciar seu tempo de estudo, pelo valor do curso, pelo acesso a cursos não disponíveis nas redondezas. Mas o que ficou claro é que em termos de educação, a modalidade a distância não corresponde ao conceito definido e dessa forma o termo ensino é o mais adequado para definir a EAD. Neste sentido a partir deste ponto adotamos o termo Ensino pra tratar da discussão sobre o aspecto distância.

Barreto (2006) acredita que a EAD venha desesterritorializar e destemporalizar a escola, o que seria um iminente perigo. Na verdade, as noções de espaço e tempo, como condições a priori para o conhecimento humano, podem ser repensadas. Tempo e espaço continuam como categorias, mas como noções também sofrem o impacto do desenvolvimento histórico-cultural. Na visão do autor na data em que publicou pode ter sido um receio natural sobre acontecimentos que transformam um comportamento convencional.

Uma década depois, Tori (2017) propõe uma nova visão sobre o mesmo aspecto, dizendo que

mesmo na modalidade presencial o aluno pode ausentar-se psicologicamente do assunto abordado pelo professor em sala de aula, sendo possível, paralelamente que em outro momento, esse mesmo aluno se mostre presente e envolvido em interações via internet. 
Não visão do autor supracitado, em muitas vezes o aluno pode até estar em sala de aula, mas o pensamento vagueia distante daquilo que o professor está apresentando e, por outro lado, alunos que estão a quilômetros de distância do professor podem estar mais engajados e serem mais participativos. Os motivos para que isso ocorra variam, talvez a metodologia de ensino do professor presencial não seja atrativa para o aluno acostumado a conviver com a informação a disposição em suas mãos, de forma fácil, rápido, atraente, por vezes resumida e filtrada. Segundo Tori (2017), para as novas gerações, o estranho é ficar sentado em uma sala, offline, sem recursos digitais que se tornaram extensões de seus corpos e mentes, seminteratividade.

Neste ponto não se pode deixar de considerar que estamos lidando com duas coisas - recreação e formação acadêmica, cujas demandas de atenção são diametralmente opostas e exigem backgrounds diferentes, além de que o processo de formação é dependente da atitude e disposição do aluno em relação a um projeto (sua qualificação). Na plataforma online de ensino é esperado que o material instrucional seja dimensionado e formatado para atingir o público e estabelecer condições para uma boa performance para o aluno, atraindo-o para o conteúdo e oferecendo uma boa experiência de imersão.

O discurso de Tori (2017) corrobora com as ideias de Paulo Freire, principalmente quando este diz que que "Não há docência sem discência" e "ensinar inexiste sem aprender" (2007, p. 23). Para Tori (2017, p. 47), a preocupação de Freire (2006) com a postura crítica do aprendiz, com sua autonomia e libertação não poderia estar mais sintonizada com os desafios contemporâneos da sociedade da Informação. Para o autor a modalidade denominada a distância facilmente pode ser rebatizada como sem distância.

Além de discutir as ideias de Freire, Tori (2017) apresenta uma abordagem ampla sobre a teoria da distância transacional de Moore (2002), que analisa a educação a distância sobre diversos aspectos/variáveis (não apenas no que se refere a separação geográfica) e que pode ser decomposta em distância espacial, ou seja, a separação geográfica entre o professor e o aluno, a distância temporal, que se refere a atividades realizadas de forma assíncrona (como em uma correspondência, convencional ou eletrônica), ou síncrona (como em um chat ou em uma videoconferência), e interativa, que se refere à distância dialética entre o professor e o aluno.

$\mathrm{O}$ que foi exposto anteriormente permite considerar que o conceito de EAD não é apenas a separação geográfica entre professor e aluno, mas sim um conceito pedagógico onde esta relação se dá quando os atores estão separados em espaço e/ou tempo (KEEGAN, 2002). Para o autor, no processo ensino-aprendizagem o conceito da "distância" - ou do seu inverso "proximidade" - pode ser mais útil, se concebido em termos de suas variáveis psicológicas e pedagógicas do que sob os fatores geográficos e tecnológicos que dominam a maior parte das discussões. Dessa forma o aporte tecnológico oferecido aos cursos na modalidade EAD é essencial para promover a transação ${ }^{2}$ online, condicionando o processo de ensino e aprendizagem.

Neste tópico a abordagem sobre a modalidade em questão em ser a distância, ou ser não presencial, ou até mesmo ser sem distância (como sugere Tori) nos levou a sugerir termo Online que, ao mesmo tempo deixa subentendido o aspecto da separação geográfica, mas também torna menos estereotipada a atual modalidade EAD. Além disso optamos pelo uso do termo Ensino no lugar de Educação, pois consideramos o discurso dos que defendem que o processo de educação requer mais complexidade do que a EAD pode oferecer. Sendo assim propomos que o termo Ensino Online (EOnline) é o mais indicado para denominar a modalidade hoje chamada de Educação a Distância.

\section{Gerenciar o conceito de "não presencial".}

Em seu discurso, Tori (2017) detalha as variáveis da extensão da distância transacional, sendo elas: o diálogo, a estrutura do programa e a autonomia do aluno. Para Tori os componentes de distância na aprendizagem poderiam manifestar-se sob as três interações educacionais identificadas por Moore: entre aluno-professor, entre aluno-aluno e entre aluno-material, visto que, devido à distância temporal,

\footnotetext{
${ }^{2}$ conceito de transação tem origem em Dewey (Dewey e Bentley 1949). Conforme exposto por Boyd e Apps (1980:5), ele "denota a interação entre o ambiente, os indivíduos e os padrões de comportamento numa dada situação".
} 
o aluno careceria de relações interpessoais com o professor e seus colegas, e, dependendo do material (como peças de um carro em uma atividade de montagem de um carro de verdade), não teria contato com o projeto.

Filatro (2008) cita que a compreensão do aprendizado eletrônico como um sistema inserido em um contexto mais amplo, implica reconhecer que a dinâmica dos processos de aprendizado eletrônico escapa não apenas dos limites de espaço e tempo, mas também extrapola a própria situação didática em si.

A gestão da modalidade Ensino Online (E-Online) é caracterizada por englobar todo o processo de administração de subsistemas que levam à criação, veiculação e implementação de um programa de E-Online, iniciando-se pela avaliação das necessidades do público-alvo (MOORE; KEARSLEY, 2007). A gestão de E-Online é proveniente de recortes desde o contexto macro da gestão educacional, passando pela diferenciação de instituições onde destacam-se as que oferecem curso a distância. A gestão da educação básica se distingue da gestão da educação superior, que apresenta distinções entre as modalidades presencial e a distância, portanto a gestão do E-Online se apresenta e deve ser tratada como distinta das demais modalidades (MILL; BRITTO, 2009).

Pra Belloni (2009), Mill e Britto (2009) as raízes da gestão educacional e, especialmente, da gestão da educação Online têm sua origem na teoria geral da administração, consolidada no século XX. Atividades de nível decisório - planejar, organizar, dirigir e controlar - e de recursos - instalações, espaços, tempo, dinheiro, informações e pessoas - se fazem presentes na gestão da educação em geral e na gestão do E-Online. Os autores ressaltam as peculiaridades na condução destas funções (planejar, organizar, dirigir e controlar) para que haja diferenciação de uma empresa tradicional visto que, para que os resultados educacionais sejam alcançados, deve-se considerar que o E-Online é um sistema complexo e exige uma gestão eficiente (BOF, 2005; SILVA, 2013). Os sistemas E-Online adequados são formados por uma série de componentes que devem ser trabalhados de modo integrado; é a formalização de uma estrutura operacional que perpassa o desenvolvimento da concepção do curso, a produção de materiais didáticos, a definição de avaliação, o estabelecimento de mecanismos operacionais para distribuição de conteúdos, a disponibilização de serviços de apoio à aprendizagem e o estabelecimento de procedimentos acadêmicos.

Considerando o acima exposto pelos autores a respeito da ausência (ou "não presença") física dos atores - característica do Ensino Online, reafirma a relevância e a complexidade com que os programa de desenvolvimentos de cursos desta modalidade, demandando esforço e trabalho em equipe extras. Todas as atribuições do grupo envolvido nos cursos de E-Online fazem com que seja imprescindível que os integrantes tenham conhecimento sobre o universo do E-Online, para que possam trabalhar afinados com os anseios e necessidade de formação dos alunos. Silva (2013) sugere que os colaboradores internos do Centros de Ensino Online (CE-Online) tenham uma formação em três níveis: administrativo, técnico e didático. Para isso, o ideal é que todos tenham uma base comum e, a partir daí uma formação específica para cada área.

É fato que o E-Online tomou força graças a mudança do comportamento das pessoas quando os computadores conectados à internet possibilitaram o acesso à informação de forma rápida e fácil, mais ainda quando os celulares se tornaram smart, possibilitando que esse acesso fosse de qualquer lugar a e hora. Não podemos deixar de considerar que, ao longo dos últimos 10 anos a preocupação das instituições de ensino em oferecer um melhor curso na modalidade Online e sua regulamentação através do decreto $\mathrm{N}^{0}$ 9.057, de 25 de maio de 2017, fez com que aumentasse a credibilidade e a confiabilidade dos cursos E-Online e que houvesse um crescimento expressivo nos últimos anos. Mas sempre haverá desafios a serem superados. Entre 2010 a 2014 o maior desafio para as instituições que ofereciam E-Online era a evasão dos alunos; em 2015 esta realidade muda e o desafio passou a ser o de inovar tecnologicamente para oferecer cursos desta modalidade; em 2016 estavam relacionados com inovações em aspectos tecnológicos e, principalmente, de abordagens pedagógicas; em 2017 os principais interesse com reação ao E-Online estão voltados para (do menos para o mais importante) Custo da E-Online, Adoção de tecnologias específicas e Definição de qualidade no E-Online (ABED, 2017; ABED, 2018 ).

Neste sentido a busca pela diferenciação ao oferecer cursos E-Online tem sido prioridade para as instituições, e os meios para que isso efetivamente aconteça tem sido discutido frequentemente. Nesta direção a participação da equipe de colaboradores que compõem os CE-Onlines tem fundamental importância, pois as funções demandas pelo E-Online requerem que os profissionais 
sejam competentes e cientes da complexidade do universo E-Online. Com um organograma bem definido a elaboração de projetos de E-Online requerem que a equipe tenha um comportamento colaborativo e proativo. Neste aspecto cada profissional tem papel fundamental. Com relação a este aspecto, pesquisas feitas em instituições que atuam oferecendo cursos E-Online declararam a participação do profissional de Design nas equipes de criação e desenvolvimento de cursos E-online, e apontaram para o exercício de função de caráter operacional para este profissional.

\subsection{O Design e a gestão como estratégia de inovação para a E-online}

$\mathrm{O}$ design está ligado a inovação a partir do momento em que existe a busca pela solução dos problemas e das necessidades do mercado, visando também a diferenciação perante a concorrência para a sobrevivência diante da competitividade (BEST, 2006; BORJA DE MOZOTA, 2003) por meio da característica articuladora e multidisciplinar do design (MARTINS E MERINO, 2008). No universo do design os autores citados apontam para uma atividade que tem capacidade de exercer intervenções em todos os níveis decisórios do contexto organizacional, desde que possua acesso global aos diversos setores organizacionais. Neste sentido os profissionais desta área podem contribuir não só com a prática do design voltada para a execução do projeto, mas também podem interferir e promover inovações nos outros níveis decisórios - estratégicos e táticos, por meio da gestão de design.

A dimensão de Gestão de Design tem muito a contribuir para o universo cientifico, onde uma abordagem que trata da relação do Design no contexto do E-Online poderia permitir que as relações das duas dimensões - Design e E-Online, estabeleçam uma relação de dependência para que a busca pela inovação e pela qualidade e que estabeleçam um patamar em que as necessidades dos alunos e as restrições de cada público sejam contornadas de forma criativa e inovadora, podendo contribuir para um maior e melhor acesso à educação às pessoas de diversas regiões.

\section{Considerações Finais}

O discurso adotado neste texto gerou uma discussão sobre o processo de ensino e educação através de vários pontos de vistas de autores conhecedores do assunto, e isso permitiu que comparássemos os pontos de vistas e chegasse a uma proposta de nova termologia para a modalidade hoje intitulada Educação a Distância.

Propor Ensino Online como termo pra a modalidade EAD é considerar que os alunos tem incorporado ao seu convívio diário as tecnologias que viabilizam o acesso a informações em ambiente virtual pela internet. Dessa forma os usuários podem ter certa experiência com interfaces de diversas categorias e condições (boas ou ruins) de navegação. Esse acesso fácil a informação por dispositivo móveis em qualquer local, quase sempre individualmente, torna o termo 'Educação' inapropriado para a modalidade, pois, de acordo com autores citados, o processo de educação é mais do que somente ter acesso, mas sim é algo que está ligado à interação entre pares, à construção do conhecimento em conjunto. Valores e condutas são construídos, sobretudo, pela convivência, relações interpessoais e experiências individuais e coletivas.

O mesmo vale para o termo 'Online' em substituição do termo 'a Distância'. Aqui tratamos do fenômeno de interação possibilitado pelas TICs onde, dito por autores aqui relacionados, possibilitam que a qualquer hora e em qualquer lugar, os alunos acessem ao conteúdo de aula, e que, por diversas vezes, estão mais presentes que muitos alunos que frequentam uma sala de aula tradicional/presencial. Dessa forma a distância deixa de ter significância, e a característica da disponibilidade facilitada do Online parece ser mais adequado para a abordagem.

Nossa proposta de uso do termo 'Ensino Online' não tem a intenção de tirar o mérito do que atualmente tem a EAD, mas sim de identificar de forma correta o potencial de transformação que reside no processo de ensino e aprendizagem conquistado por essa modalidade e despertar para a importância de se considerar os aspectos que dizem respeitos ao novo comportamento dos indivíduos ao conviverem com ambientes digitais, suas experiências, expectativas, dificuldades nesse processo, para que não se transforme um Ambiente Virtual de Aprendizagem em uma barreira para o desempenho do aluno, tornando ou conteúdo desinteressante e perdendo para outros também disponíveis a poucos cliques ou toques na tela. 
Distance Education, Distance Teaching or Non-Presential Teaching: what is it about and how to innovate in access to knowledge in the digital age?

Abstract: This article is the result of a discussion on the topic of Distance Education and Management Innovation, over the 3 years prior to the Covid-19 pandemic. The purpose of this article is to promote dialogue on the terms education, teaching, physical distance, virtual presence and thereby identify how it would be possible to find a more suitable nomenclature for teaching activities remotely. Throughout the conception of this research, social distance has emerged, and remote activities have become constant in the various channels that deal with education, making the subject of teaching and education mediated by fashionable digital platforms. The bibliographical survey served to guide the construction of the discourse. As a result, it was realized that the path of the intense search for quality education can be obtained through the process of innovation in management and that the fundamental principles of EAD can increasingly allow a search for the democratization of quality education, but that the Education should be used with caution when there is distance.

Keywords: Distance education; Distance learning; Innovation; Management; Design Management

\section{Referências bibliográficas}

BARRETO, G.B. Política de Educação à Distância: a flexibilização estratégica. In: LOPES, A. C.; MACEDO, E. (orgs.). Políticas de Currículo em Múltiplos Contextos, São Paulo: Cortez Editora, 2006. $269 \mathrm{p}$.

BELLONI, M. L. Educação a distância. 5a ed. Campinas: Autores Associados, 2009.BOF, 2005.

BEST, K.. Gestão de design: gerir a estratégia, os processos e a implementação do design. Lisboa: Diverge Design S.A. 2006.

BRASIL. INEP. Número de alunos de curso à distância cresce $\mathbf{6 2} \%$. Disponível em http://www.INEP.org.br, acesso em 10 de fevereiro de 2019.

CHAVES, Eduardo O. C. Tecnologia na educação, ensino a distância, e aprendizagem mediada pela tecnologia: conceituação básica. Revista Educação da Faculdade de Educação da Pontifícia Universidade Católica de Campinas, ano III, número 7, novembro de 1999 [on line] Disponível: http://www.edutecnet.com.br/Textos/Self/EDTECH/EAD.htm [Texto capturado em 02 de janeiro de 2020].

CONSOLO, Adriane. Ensino a Distância ou Educação a Distância. 2014. Acesso em 21 de março de 2019. https://www.moodlelivre.com.br/tutoriais-e-dicas/740-ensino-a-distancia-ou-educacao-adistancia

DEMO, Pedro. Questões para a teleducação. Petrópolis, RJ: Vozes, 1998.

FILATRO, A.; CAIRO, S.. Produção de conteúdos educacionais: design instrucional, tecnologia, gestão, educação e comunicação. São Paulo: Saraiva, 2016.

FILATRO, A. Design instrucional na prática. São Paulo: Pearson Education do Brasil, 2008

FREIRE, P. Pedagogia da autonomia: saberes necessários à prática educativa. 33 ed. São Paulo: Paz \& Terra, 2006.

JESUS, Osvaldo Freitas de. Dilema: educação a distância ou ensino a distância? Profissão Docente: On line, Uberaba, v. 13, n. 29, p.82-93, jul. 2013. Semestral.

KEEGAN, D. Theoretical Principles of Distance Education. London: 1993. In. ABED. Teoria da Distância Transacional. Revista Brasileira de Aprendizagem Aberta e a Distância, São Paulo, Agosto, 2002 
MOORE, M. G. Teoria da Distância Transacional. Publicado em Keegan, D. (1993) Theoretical Principles of Distance Education. London: Routledge, p. 22-38. 2002.

MOORE. Michael G; KEARSLEY, Greg. Educação a distância: uma visão integrada. São Paulo: Thompson Learning, 2007.

MILL, D.; BRITO, N. D. Gestão da educação a distância: origens e desafios. $15^{\circ}$ CIAED Congresso Internacional ABED de Educação a Distância, 2009, Fortaleza. Anais... Fortaleza: CIAED, 2009.

TORI, R. Educação sem distância: as tecnologias interativas na redução de distâncias em ensino e aprendizagem. São Paulo: Senac São Paulo, 2017.

ROMANZIN, C. D. Ensino A Distância, Educação a Distância, Aprendizagem a Distância: Conceitos e Diferenças, 2001.

SILVA, Robson Santos da. Gestão de EAD: Educação a Distância na Era Digital. São Paulo: Novatec, 2013.

SLOTERDIJK, P. Regras para o parque humano. Uma resposta à carta de Heidegger sobre o humanismo. Trad. José Oscar de Almeida Marques. São Paulo: Estação Liberdade, 2000.

MOZOTA, B. B. Design management: Using design to build brand value and corporate innovation. Nova Iorque: Allworth Press. 2003

MARTINS, R. F. de F.; MERINO, E. A. D. A Gestão de Design como estratégia organizacional. $2^{\mathrm{a}}$ ed. Londrina: Eduel; Rio de Janeiro: Rio Books, 2011. 